\title{
HISTORICAL PERSPECTIVES OF THE AMERICAN ASSOCIATION FOR THORACIC SURGERY
}

\section{WILLY MEYER (1858-1932)}

W illy Meyer, the second president of the American Association for Thoracic Surgery and realistically its founder, was born in Minden, Westphalia, in 1858. Broadly educated and talented, he chose medicine over a professional career in music largely because of family friendship with Dr. Abraham Jacobi who, exiled to America, had become a founder of the German Hospital in New York. After 6 months of military service, Meyer entered the University of Bonn, from which he received a medical degree in 1880 .

After another year as an army surgeon during the aftermath of the Franco-Prussian War, he returned to Bonn for 3 fruitful years as clinical assistant to Trendelenburg. They remained lifelong friends.

In 1884 at the age of 26 years, Willy Meyer emigrated to New York. He promptly developed a successful general practice. Within 2 years he was able to limit his practice to surgery and also obtain a valued appointment to the distinguished staff of the German Hospital, now the Lenox Hill. The scope of his activities was broad. He is credited, for example, with the introduction of the cystoscope to this country, ureteral catheterization, staged prostatectomy, newer methods of gastrostomy, and, in 1894, independent of Halsted, radical mastectomy for cancer of the breast. There is little question, however, that his contributions to thoracic surgery are his passport to history.

Meyer identified the beginning of intrathoracic surgery with Sauerbruch's demonstration of his negative-pressure chamber, which Sauerbruch developed in von Mikulicz's department in Breslau. There in 1904, Meyer watched Sauerbruch perform an esophagectomy in a dog anesthetized in a negative-pressure chamber. Meyer thought of bringing such a chamber to the German Hospital but was dissuaded from doing so by Sauerbruch. In 1908 a blue ribbon session was held at the Chicago meeting of the American Medical Association to determine the relative merits of negative and positive "differential" pressure in the management of open thoracotomy. Meyer had the honor of opening the discussion. Relative merits were hotly argued without conclusion. As a result, however, Meyer and his engineering colleagues at the German Hospital built a modification of the Sauerbruch chamber that would allow the choice of negative or positive pres-

J Thorac Cardiovasc Surg 1996;111:1112

Copyright (C) 1996 by Mosby-Year Book, Inc.

$0022-5223 / 96 \$ 5.00+0 \quad \mathbf{1 2 / 5 4 / 7 1 3 0 1}$ sure at will. This super chamber was used in the experimental laboratory but never clinically.

At the 1913 meeting of the American Medical Association, Willy Meyer presented a lengthy report of the first successful resection of the thoracic esophagus. This had been done by his colleague, Franz Torek. To Meyer's surprise and disappointment, there was no discussion! This indifference convinced him of the need for a special society in which thoracic surgical problems could be thoroughly discussed. Conventional wisdom held that aside from empyema, possibly bronchiectasis, and chest wall tumors, few disẹses of the thorax could be addressed surgically. Cancer of the lung was hardly worthy of mention, tuberculosis out of bounds, and cardiac surgery the "music of the future."

Recognizing the limits to an individual trying to form a national society, Meyer adopted the strategy of a staged attack, beginning with a small group of New York surgeons. One must admire the smoothness of his operation. On February 20, 1917, twenty invited friends met in his office and agreed to form The New York Association for Thoracic Surgery, with Willy Meyer chairman. High on its agenda was the founding of a national association. In March of 1917 a national list of prospective members, including physicians from related fields, were invited to an organizational meeting of a national society called for June 7, 1917, at the Waldorf Astoria. At that time his close friend Samuel Meltzer was elected president. The first scientific meeting of the newly formed American Association for Thoracic Surgery was held in Chicago in June of the following year, 1918. At that meeting Willy Meyer, elected to succeed Meltzer as president, justified the new society in a review of the state of thoracic surgery.

Willy Meyer served two terms as president while continuing his active general surgical practice and active participation in surgical meetings. He died suddenly in February 1932 at the age of 74 years, while attending a meeting of the New York Academy of Medicine. The subject of the evening was cancer of the breast and he had risen in defense of his surgical approach to this disease.

J. Gordon Scannell, MD 